\title{
Theoretical Setting, Mathematical Model and Operating Principles of an Innovative System, Based on Natural Evaporation Processes, for Salty and Brackish Water
}

\section{Purification}

Farné Stefano

Department of Industrial, Electrical, Computer and Biomedical Engineering, University of Pavia, Italy.

\section{ABSTRACT}

The problem of the scarcity of fresh water is incredibly pressing and constantly increasing due to population growth and consumption. Investing in the development of sustainable systems for brackish and sea water desalination remains one of the key points on which it is worthwhile to concentrate our efforts to solve this problem. Moreover, the need of replacing fossil fuels in many areas of human activities is strongly felt, in particular for the primary resource fresh water, that must be regenerated, where the natural availability is not present or it has been depleted. The technologies for the production of desalinated water, normally make use of electrical (reverse osmosis) or thermal energy (distillation using gas/oils combustion) from fossil sources. The technology presented in this paper has been named "Solar Desalination Geoassisted Continuous", an innovative system for salty and brackish water desalination, covered by an Italian patent, made-up and registered by Stefano Farné and Vito Lavanga, almost totally exploiting solar power and capable of producing distilled water with very low running costs compared to current technologies. The SDGC system effectively obtains water evaporation and is able to function only by integrating losses due to the not perfect thermal insulation of the materials.

Keywords: Desalination, Water, Renewable energy.

\section{State of the Art}

Desalination of sea water or brackish water is used in the production of drinking water, whose acceptable salinity limit is $500 \mathrm{mg}_{T D S} / l$ (TDS: total dissolved solids), or in the production of demineralized water for industrial applications, such as the water used in steam boilers or power plants, where the level of salinity must be significantly lower, sometimes less than $10 \mathrm{mg}_{T D S} / l$ (World Health Organization, 2017).

\subsection{Characteristics of salty water}

Sea water can be considered a solution of pure water and salts of various kinds, the quantity of which is not constant but is subject to variability depending on the location, the season and the surrounding anthropic activities. However, it can be stated that, on average, sea water has the following characteristics (Rognoni, 2010):

- pH: $7.6-8.4$;

- Density at $20^{\circ} \mathrm{C}$ : around $1025 \mathrm{~kg} / \mathrm{m}^{3}$;

- Conductivity at $20^{\circ} \mathrm{C}: 48,000-60,000 \mu \mathrm{S} / \mathrm{cm}$

- Dissolved air: $20-28$ ppm;

- Salinity TDS: 34,000 - 45,000 ppm.

Among the average parameters reported, the most important is certainly salinity, because it quantifies the total amount of dissolved salts. Based on this parameter, water is divided into four categories (Rognoni, 2010):

- Fresh water: $<450$ ppm;

- Brackish water: 500 - 30,000 ppm; 
- Sea water: $30,000-50,000$ ppm;

- Brine: $>50,000$ ppm.

\subsection{References to the thermodynamics of desalination}

The principle of sea water desalination is represented in the following chemical reaction: (Rognoni, 2010; Cipollina et al., 2009):

$$
\left[\mathrm{H}_{2} \mathrm{O}\right]+[\mathrm{NaCl}] \Leftrightarrow\left[\mathrm{H}_{2} \mathrm{O}+\mathrm{NaCl}\right]+\mathrm{E}
$$

Where, $E$ represents:

- dissolution heat: heat released during the melting of a salt in water;

- osmotic pressure: difference in pressure that is created when the osmotic membrane is placed between two solutions with different concentrations;

- ebullioscopic gradient: difference in evaporation temperature of a solution compared to pure solvent.

$E$ therefore represents the minimum primary energy to be supplied so that transformation takes place and is independent of the process used, the value of which can be calculated by introducing a quantity of salt into a cubic meter of water sufficient to create a solution of water and salt equivalent to the marine one and measuring the increase in temperature due to the exothermic reaction. By performing this measurement, a temperature variation of about $0.64{ }^{\circ} \mathrm{C}$ is obtained, corresponding to $0.75 \mathrm{kWh} / \mathrm{m}^{3}$ (Rognoni, 2010; Cipollina et al., 2009).

To this value we must add the energy necessary to overcome the inefficiencies of technologies derived from the complex systems put in place to carry out the transformation.

\subsection{Overview of the main existing technologies}

This section will illustrate the main technologies adopted in common industrial practice, reporting some examples of plants in operation.

\subsubsection{Evaporative plants}

These are based on the evaporation of salt water and the subsequent condensation of humidified air using thermal or electric energy through conventional sources. In the more recent systems, however, a portion of the total energy is supplied by a solar energy system, thus constituting a hybrid system (Cipollina et al., 2009; Rognoni, 2010).

\subsubsection{Multistage flash (MSF)}

This is composed of a series of successive stages, each equipped with a heat exchanger and a condenser, maintained at decreasing pressure so that the temperature in each chamber is always kept above the boiling point (Figure 1).

The incoming water is pre-heated following the passage through the condensers present inside each stage at the expense of the thermal energy possessed by the steam inside the stage itself, which will be subject to a condensation process. Subsequently, the fluid is heated up to the saturation temperature after which it is sent to the first stage, 


\section{AJAST}

Asian Journal of Applied Science and Technology Volume 4, Issue 3, Pages 183-209, July-September 2020

where the temperature will be much higher than the internal pressure, causing a very rapid evaporation of a part of the salt water.

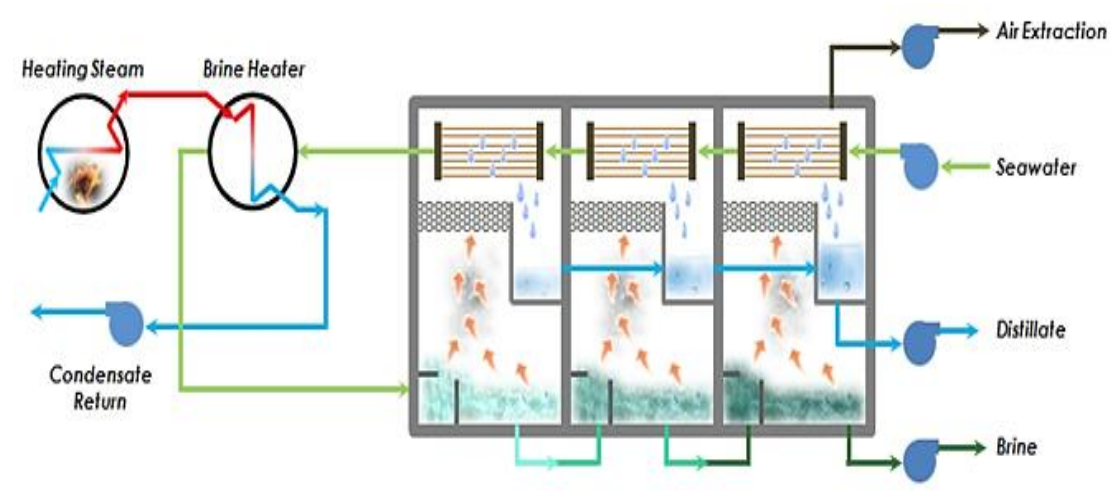

Fig.1 MSF plant layout (source: STX Heavy Industries)

The formed vapor will condense on the heat exchanger preheating the incoming water and the condensate produced will be conveyed to the outside. The remaining salt water will be at a lower temperature than the saturation temperature and will therefore be sent to the next stage, characterized by a higher degree of depression, repeating the process. (Cipollina et al., 2009).

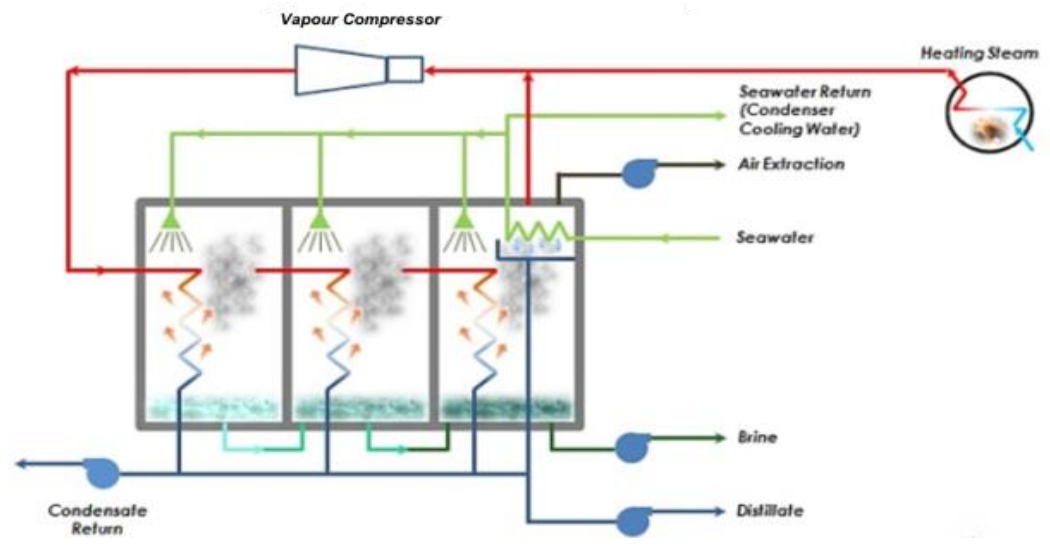

Fig.2 MED plant layout (source: STX Heavy Industries)

The following is some data concerning existing plants in which significant use of solar energy has been used (Tzen, Zaragoza, \& Alarcòn Padilla, 2012, p. 534):

- $\quad$ Lampedusa (Italy): powered by $408 \mathrm{~m}^{2}$ of solar panels, produces $7.2 \mathrm{~m}^{3} / \mathrm{d}$;

- San Luiz de la Paz (Mexico): powered by $194 \mathrm{~m}^{2}$ of conventional solar panels and by $160 \mathrm{~m}^{2}$ of concentrating solar panels, produces $10 \mathrm{~m}^{3} / \mathrm{d}$;

- El Paso (Texas): formed by the combination by $3355 \mathrm{~m}^{2}$ of solar with a cogeneration plant. The plant produces electricity through a Rankine cycle and fresh water through a twelve-stage system. It produces $19 \mathrm{~m}^{3} / d$ of fresh water.

\subsubsection{Multiple effect distillation (MED or ME)}

Taking advantage of the same principle adopted by the MSF technology, this uses a reactor instead of the vaporization chamber (Figure 2). The incoming water is preheated by the thermal energy contained in the steam 
coming out of the last effect (or stage), after which it is sent simultaneously to the top of all the effects and diffused internally through suitable sprayers. Within each effect there is a heat exchanger that transfers thermal energy to the salt water but, of all the effects present in the system, only the first receives the energy directly from the heat generator; the other effects placed in the cascade receive energy through the steam formed in the previous effect, which transfers heat through the heat exchanger and condenses. Among all the effects present, therefore, the first will have the task of supplying the steam necessary for the whole process, while the task of producing the distillate will be entrusted to all the other subsequent effects (Cipollina et al., 2009).

There follows some data concerning existing plants (Tzen et al., 2012, p. 534):

- Abu Dhabi (EAU): powered by $1862 \mathrm{~m}^{2}$ of solar panels, produces up to $120 \mathrm{~m}^{3} / \mathrm{d}$;

- Plataforma Solar de Almeria (Spain): powered by $500 \mathrm{~m}^{2}$ of concentrating solar panels, produces $72 \mathrm{~m}^{3} / \mathrm{d}$.

\subsubsection{Membrane Processes}

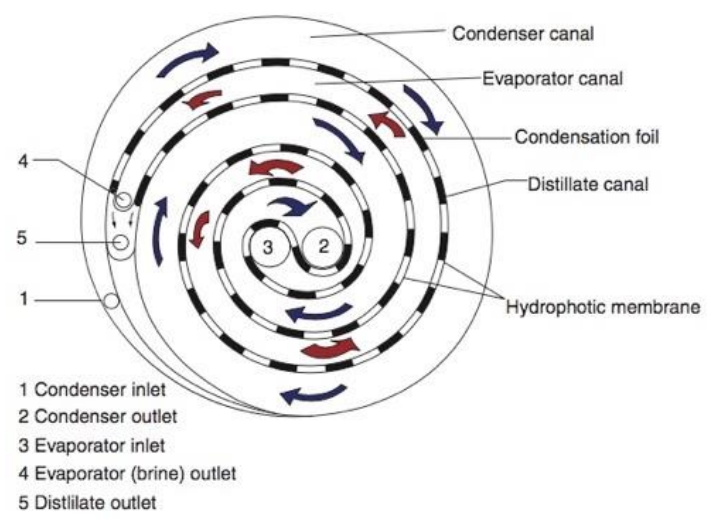

Fig.3 MD plant operating scheme (source: Tzen, Zaragoza, \& Alarcòn Pasilla, 2012)

These create a separation between two fluids by applying a driving force to a selective barrier that is permeable only by some of the substances present in the fluid. The different types of processes are discriminated according to the source that produces the driving force: electrodialysis (exploits the action of an electric field), filtration (exploits a pressure gradient), osmosis (exploits the chemical potential), or dialysis (exploits the concentration gradient). Among these, the most commonly applied in the field of desalination is reverse osmosis; in the following we will also introduce the MD (membrane distillation) process, which is the most recent of all membrane processes.

\subsubsection{Reverse osmosis (RO)}

The feed water is sent at high pressure to the high salinity compartment and flowed to the low salinity compartment of a semi-permeable membrane, reversing the osmosis process. The layout of the plant is relatively simple and consists of only a few elements (membranes, hydraulic pumps, pre-treatment systems and energy sources) but, nevertheless, this has become competitive only recently due to the cost of the membranes and maintenance. In fact, they are subject to fouling and incrustation caused by the precipitation of poorly soluble salts and this requires frequent maintenance. The efficiency of membrane removal varies according to the substances dissolved in the water, so a single stage is often not sufficient to give the finished product the necessary quality. The operating 
pressures are in the range of $50-80 \mathrm{bar}$, beyond which it is possible to overcome the mechanical resistance of the membranes. One of the most important plants is located at Lampedusa (Italy) (Tzen et al., 2012, p. 553): the system is able to provide $120 \mathrm{~m}^{3} / d$ of desalinated water through two RO units and the supply of electricity takes place via a $100 \mathrm{~kW}_{p}$ photovoltaic plant equipped with accumulation systems. The incoming water is pretreated, through filtration processes and through the introduction of chemical substances, to prevent fouling and corrosion phenomena and the salt content in the obtained water is lower than $500 \mathrm{ppm}$, in compliance with the drinking water specifications established by the World Health Organization (Rognoni, 2010).

\subsubsection{Membrane distillation (MD)}

The incoming water is heated and evaporated, after which it comes into contact with a hydrophobic membrane that allows the passage of steam but not water. After passing through the membrane, the vapor comes into contact with a colder surface, where it condenses, producing fresh water that naturally flows towards the outlet of the system. The simplicity and the ability to operate with small differences in temperature make this a technology of considerable interest and, operating also at lower temperatures than the common distillation systems $\left(50-80{ }^{\circ} \mathrm{C}\right)$, solar energy can be easily exploited (Figure 3). Over time many pilot plants have been built and have given encouraging results. A $0.05 \mathrm{~m}^{3} / d$ desalination plant was built at New South Wales University in Australia; it exploits $3 \mathrm{~m}^{2}$ of solar panels. In the last ten years, several MD systems have been implemented within European projects (SODESA, MEMDIS and SMADES). The Fraunhofer Institut in Germany has developed compact solar MD modules that make it possible to achieve $10-30 \mathrm{l} / \mathrm{h}$ of distillate, working at $55-85^{\circ} \mathrm{C}$ and providing $300 \mathrm{l} / \mathrm{h}$ of water in input. The system requires approximately $90-200 \mathrm{kWh} / \mathrm{m}^{3}$ of thermal energy and does not require inlet water pre-treatment systems (Tzen et al., 2012, p. 543). Given the semi-experimental nature of this technology, the literature reports very wide energy consumption and fresh water costs ranges, between $1-$ $9000 \mathrm{kWh} / \mathrm{m}^{3}$ and $0.28-123 € / \mathrm{m}^{3}$ respectively (Reddy \& Sharon, 2014, p. 1109).

\subsubsection{Renewable sources processes}

To date, around the world, to produce $1000 \mathrm{~m}^{3} / d$ of fresh water $10 \mathrm{kTOE} / \mathrm{y}$ are necessary, and that is why in recent years new systems powered by renewable sources have taken hold. The most commonly used sources in desalination are solar, wind and geothermal. Among these, the solar energy plays a particularly important role because it accounts for 57\% of all production (Reddy \& Sharon, 2014, p. 1081). The systems shown below do not allow a particularly high production; however, they become competitive where there is a large availability of one of the renewable sources mentioned.

\subsubsection{Solar chimney}

This converts solar energy into kinetic energy of the air, which is in turn converted into electricity thanks to turboalternators. The system consists of a circular basin filled with salt water and covered with glass panels. The solar radiation that crosses the glazed surface develops within the phenomenon of the greenhouse effect. The heated air will therefore tend to go up the chimney, thus turning the wind blade installed transversely to the base of the chimney and connected to an electric generator (Figure 4). 


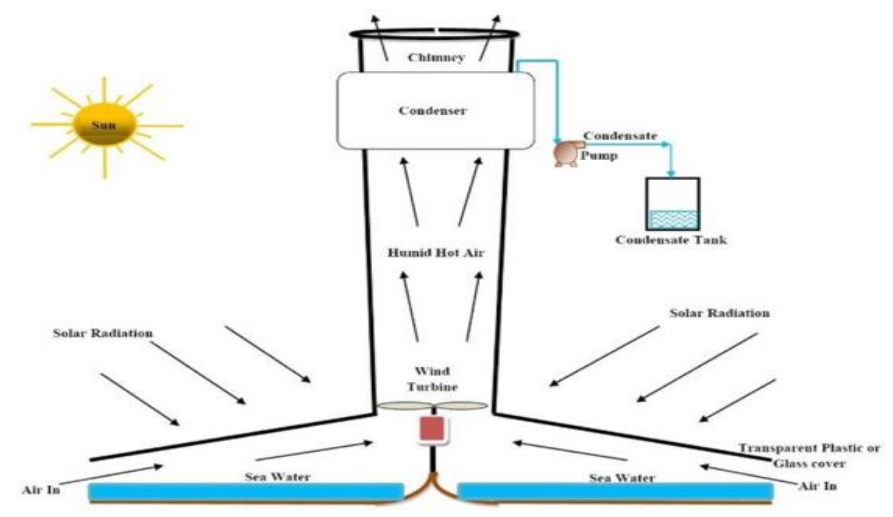

Fig.4 Solar chimney variant plant layout (source: Reddy \& Sharon, 2014)

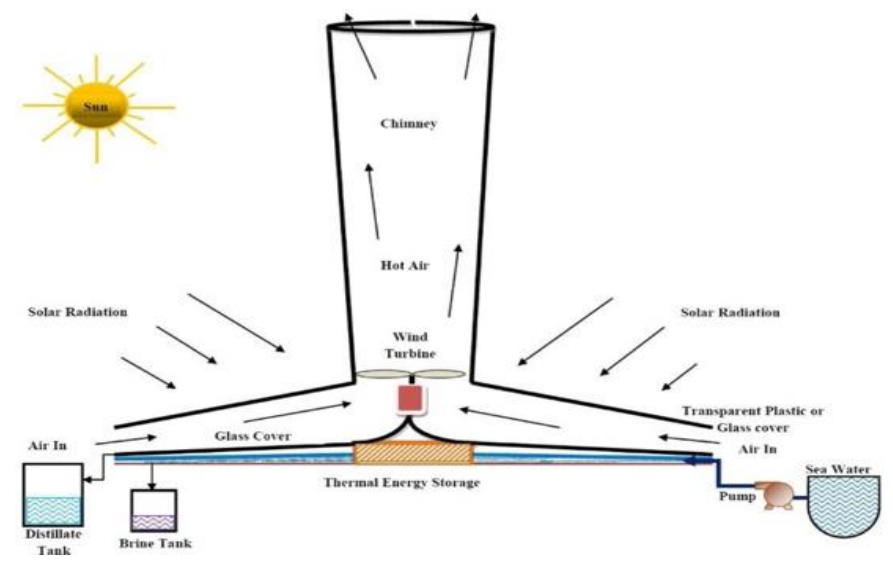

Fig.5 Solar chimney plant layout (source: Reddy \& Sharon, 2014)

At the same time, the air that tends to rise along the chimney is in contact with the heated salt water present in the basin, which therefore tends to evaporate, increasing the internal humidity. The humidified air condenses in contact with a second glass plate characterized by a lower dew point temperature and the condensate is conveyed outside the plant. A variant of this system consists in removing the glass plate on which the steam condenses and replacing it with a high efficiency condenser placed on the top of the chimney, as shown in Figure 5. Plants of this type have a production cost of about $2 € / \mathrm{m}^{3}$ if they operate for $8 \mathrm{~h} / \mathrm{d}$ (Reddy \& Sharon, 2014, p. 1084).

\subsubsection{Solar still}

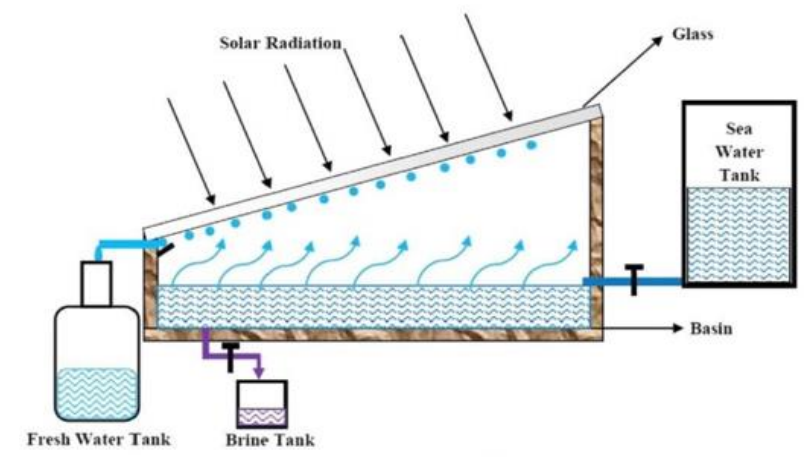

Fig.6 Solar still plant layout (source: Reddy \& Sharon, 2014) 
This plant is formed by a tank filled with salt water, closed on the top by a transparent glass plate, kept at a temperature below the dew point, that is able to allow the heating and the subsequent evaporation of the water present on the inside (Figure 6) as well as acting as a condenser for the system.

The main advantage of this system lies in its simple construction and the use of economically cheap materials; it also requires little maintenance. The simplicity, however, has some negative implications, represented by the low efficiency and low producibility.

Although many studies are trying to improve their performance, most of these plants have an efficiency of around $30-45 \%$, mainly due to the impossibility of recovering the latent heat of condensation, which is dissipated in the environment through the exchange plate; in addition, the production of fresh water is less than $5 \mathrm{l} / \mathrm{m}^{2} \mathrm{~d}$. Studies on multiple effect systems have allowed a partial recovery of the latent heat, pushing the yield up to $57 \%$ and production up to $13 \mathrm{l} / \mathrm{m}^{2} \mathrm{~d}$, obtained through the use of large mirrors to increase the incident solar radiation and the temperature inside the tank. However, this leads to greater plant complexity and higher costs.

A large solar still plant was installed in 1967 on the island of Patmos, Greece. The structure exploits a $8640 \mathrm{~m}^{2}$ basin and production is around $26 \mathrm{~m}^{3} / d$ (Tzen et al., 2012, p. 541; Reddy \& Sharon, 2014, p. 1081).

\subsubsection{Solar humidification-dehumidification (HDH or HD)}

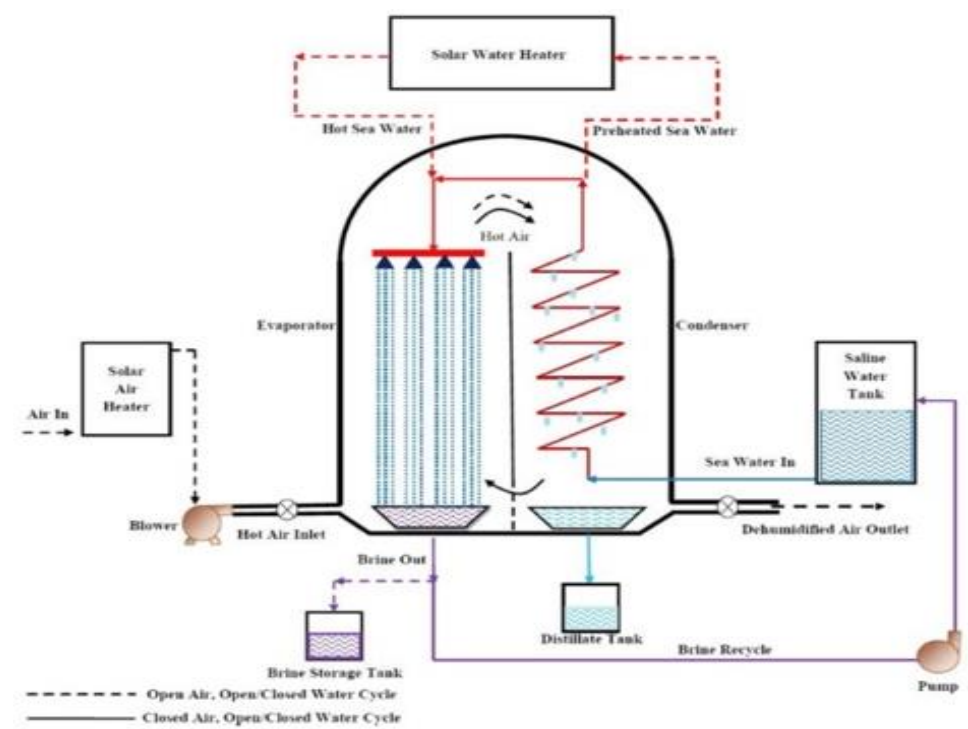

Fig.7 HDH plant layout (source: Reddy \& Sharon, 2014)

The humidity of an air flow is increased by circulating it through an evaporator in which heated salt water is sprayed. The humidified air is passed inside a condenser, from which the distillate is extracted (Figure 7).

The system consists of a heater, a humidifier and a dehumidifier and the production potential depends essentially on the flow of air and the temperature of the feed water. Productivity can be increased through a cycle of water and air preheating and, to ensure maximum exploitation of the system, there is always an optimal relationship between the flow of air and the amount of water entering the humidifier, as a function of the water temperature entering the dehumidifier and that of the condenser. The most efficient configurations are represented by MEH, multi-effect 
systems in which the production cost of fresh water is around $3-7 € / m^{3}$ (Reddy \& Sharon, 2014, p. 1083; Tzen et al., 2012, p. 544).

\subsection{Literature review}

Paragraph 1.3 presented the main technologies that are currently under the attention of researchers. From the analysis of the scientific literature on the subject, and filtering the results on the basis of technologies comparable to the SDGC system, it is clear how the topic is being treated in depth from the technological point of view, while it is lacking in studies that give an economic analysis to allow a better understanding of the situation. This is mainly due to the highly experimental nature of much of the research, which is too recent to be able to extend the analysis to the economic and technical feasibility.

The analysis shows that research on desalination systems, aimed at achieving production levels comparable with conventional technologies, finds fertile ground in HDH systems. Analysing the literature and comparing the various studies, it emerges that the common analysis data sees the main obstacle to the development of higher productivity in terms of distilled water. This aspect is dealt with in different ways: by improving the contact surface between the air and the water through the insertion of porous plastic elements to promote the humidification phase, as presented by (Chang, Zheng, Yang, Su, \& Duan, 2014, p. 254), who were able to increase productivity to $63.6 \mathrm{~kg} / \mathrm{h}$ with relatively contained specific costs of $4.4 \$ / \mathrm{m}^{3}$, or simply increasing the number of stages, as explored by (Hamed, Kabel, Omara, \& Sharshir, 2014; Reddy \& Sharon, 2014, p. 1081). In particular, the study on a double effect plant was developed by (Kang, Yang, Chang, Zheng, \& Duan, 2014) in which, even by the reuse of condensation heat and the heat possessed in the brine, it is possible to reach a range of $72.6 \mathrm{~kg} / \mathrm{h}$, at the expense of a considerable plant complexity compared to the solution proposed by (Chang et al., 2014, p. 254).

A second solution is presented by (El-Agouz, Abd El-Aziz, \& Awad, 2014, p. 278) and consists of a variation of the method by which the feed water is introduced into the system; by spraying it through a spray system instead of using a rain dispenser, the evaporation and condensation phase is encouraged, obtaining $9 l$ distilled flow rate per unit area of solar collectors installed at relatively low cost, in the order of $0.03 \$ / l$.

A third solution regarding the increase in the distilled product flow was analyzed by (Yildirim \& Solmus, 2014, p. 570) and (Bacha, 2013), according to which it is possible to increase the performance of the system by increasing the flow of air entering the system up to a limit (optimal value) beyond which it is no longer possible to obtain benefits. The same study also denied the thesis of ( $\mathrm{Li}$, Yuan, Wang, Li, \& Xu, 2014) according to which benefits could be obtained from preheating the incoming air for the purpose of increasing the relative humidity.

A second problem faced by the researchers mentioned concerns the uncertainty and the daily variability of productivity: the exclusive use of solar energy without accumulation systems to guarantee the needs (thermal and / or electric) causes a daily oscillation of the distillate flow rate, reducing its producibility. On the other hand, the integration of storage systems would increase total costs to the detriment of economic sustainability, but in the literature examined no comparative analyses were carried out to support this. The variability of the energy source is a problem that affects all renewable energy sources applied to any desalination technology; the study conducted by 
(Park, Schafer, \& Richards, 2012, p. 867-874) specifically analyses the effect of power variability on a reverse osmosis desalination plant fed directly by a wind energy plant, showing how, in the absence of power supply, a passage of salt occurs through the membranes, reducing the quality of the product. From this we can understand how the continuity of the energy source is important not only for the quantity of daily product, but also for its quality. At present, therefore, HDH systems are the ones most studied by researchers, who claim that systems of this type powered exclusively through renewable sources are applicable only on a small scale, due to the high investment cost, in relation to the production level reached.

In the literature there is also a limited contribution to the development of solar still systems: from the study carried out by (Manokar, Murugavel, \& Esakkimuthu, 2014, p. 310) it emerges that the system is influenced by a number of variables that cannot be controlled by man, including the available solar radiation, humidity and environmental temperature, meteorological conditions, and wind speed, while the parameters on which we can act are plant orientation, roof inclination, construction materials and process temperatures. The studies also show that the main problem concerns the large surface necessary to ensure satisfactory producibility in passive systems which increases the total costs of planting.

To compensate for the need for space reduction with the achievement of a satisfactory range, some solutions have been developed: the use of auxiliary systems to preheat the feed water and thus increase the production per unit area has been addressed by (Reddy \& Sharon, 2014, p. 1081) through the use of solar collectors or with the aid of mirrors capable of increasing the incident radiation per unit area. The same study shows that the low performance of the plant is also due to the lack of recovery of latent condensation heat, which can only be used in multi-effect plants with significantly increased plant costs. A second study addressed by (Ayoub \& Malaeb, 2014, p. 29) instead provides for increasing the evaporating surface by inserting a rotating cylinder into the system.

The study argues that, according to the calculations performed, with this system productivity can be improved by an order of $200-300 \%$ compared to standard passive systems. This allows the reduction of the surface required for equal productivity; however, this solution is reflected in the specific production cost, which varies in the order of $6-30 \$ / \mathrm{m}^{3}$ and is higher than conventional passive systems due to the increased complexity of the system and therefore higher operating costs. Still in the field of technological solutions powered by renewable sources, (Reddy \& Sharon, 2014, p. 1083) analyze the operation of solar chimneys, showing how, as a passive system, the operation cannot be prolonged efficiently beyond $8 \mathrm{~h} / \mathrm{d}$, by virtue of the amount of useful solar radiation available.

This is negatively reflected in the producibility and the specific production costs, evaluated by experimental plants as $2.23 \$ / \mathrm{m}^{3}$. The study also shows that the structure of these plants is large and very complex, which therefore implies high implantation and operating costs (not reported in the literature). To compensate for these costs, the system can be integrated with a series of wind turbines for the production of electricity.

Even traditional technologies, specifically the MSF plants, are being studied. These plants, typically adopted for high production, are generally fed from fossil sources. The aim of these studies is to replace conventional sources with economically sustainable technologies in the long run. The study conducted by (Reddy \& Sharon, 2014, p. 
1085) states that the use of MSF plants powered by solar energy can reach production orders up to 30 times higher than that achieved with solar still systems and with lower costs. Often, however, the energy produced by solar plants is not sufficient to cover the needs (given the randomness of the source itself) and they are therefore often coupled to power plants, in order to use the waste heat. An interesting study conducted by (Salata \& Coppi, 2014, p. 614) plans to use solar ponds together with an absorption heat pump to preheat sea water to a temperature around $100^{\circ} \mathrm{C}$. According to the study, in fact, thanks to the high concentration gradients of the salts between the surface and the bottom of the solar ponds, there is a temperature inversion effect that brings the lowest layer of water to a higher temperature than that on the more superficial surface. Under the right conditions, solar ponds with depths of over one meter have a temperature difference of $50-60{ }^{\circ} \mathrm{C}$, which maintains average values throughout the year (Ramadan, El-Sebali, Aboul-Enein, \& Khallaf, 2004, p. 64), making it usable as a seasonal solar thermal energy collector. However, the study shows that, given the high surface area required for solar ponds, the system is only suitable for small-scale installations.

Another solution presented by (Kabeel \& El-Said, 2013, p. 12) introduces a change to the MSF solar-powered system. By exploiting flash evaporation like traditional systems, it uses a heat carrier fluid enriched with nano-particles that favors the performance of the plant in terms of productivity. This makes the MSF system practicable on a small scale and it can reach specific levels up to $7.7 \mathrm{l} / \mathrm{d}$ per unit area of solar collectors. To date, estimated production costs are quite high, in the order of $11.7 \$ / \mathrm{m}^{3}$, and the installation costs (not shown) are mainly due to the cost of the collectors and of the water heating system. It is expected that increasing the performance of this portion of the system will reduce the specific cost by $63 \%$.

The literature also reports some experimental plants built with the aim of obtaining an autonomous system that can be used to purify water in areas without adequate infrastructure for water supply. The study conducted by (Schafer, Remy, \& Richards, 2004, p. 233-243) analyses the functioning of a desalination plant that combines solar technology with a membrane system, fed by waters with different chemical composition. The results show how, while using a simple and inexpensive system, the plant is able to produce drinking water with specific consumption varying between $5.5 \mathrm{kWh} / \mathrm{m}^{3}$ and $26 \mathrm{kWh} / \mathrm{m}^{3}$ according to the degree of salinity of the incoming water. The use of membranes, however, raises a series of problems due to the phenomenon of fouling that characterizes this technology and which increase the maintenance costs of the plant.

Since the membrane technology is widely adopted, there are several studies that analyse this complication with the aim of limiting its effects: the analysis conducted by (Nam, Seockheon, Dooil, Seungkwan, \& Ji, 2011, p. 1573-1579) studies the influence that the different materials constituting the membranes have on the phenomenon of dirtying them, while (Cervinia, Masaki, Tetsuji, Satoshi, \& Wataru, 2016, p. 308-318) studies the effect of biofilm formation on the inorganic suspended solids accumulated inside the membranes, highlighting how a very thorough pre-treatment of the feed water is fundamental in membrane systems, to avoid further aggravating the membrane fouling.

The literature review presented in this section shows how the research on evaporative desalination systems powered by solar energy is full of potentially valid solutions, but that these still have some limits that have not been 
Asian Journal of Applied Science and Technology Volume 4, Issue 3, Pages 183-209, July-September 2020

completely overcome. As can be deduced from the previous lines, researchers are grappling with the need to obtain satisfactory production levels while keeping the complexity of the system, and therefore the related costs, at economically sustainable levels. From the solutions presented, we note how the superficial encumbrance of the systems is a limiting factor for the applicability of some large-scale systems, both for technical issues related to the possibility of realization, and for economic issues related to installation costs in relation to the production level obtainable. Another critical issue concerns the operation of the plants: the exclusive exploitation of solar energy, without the addition of energy storage systems, makes the production of fresh water erratic and subject to weather conditions. The randomness of solar energy, characteristic of all renewable sources, limits the operation of the plant to only daylight hours, thus increasing the cost per unit of production and compromising the quality.

The analysis of the state of the art therefore shows that the new systems fed through the exclusive exploitation of solar energy cannot yet be used for the desalination of large quantities of water. On the contrary, the integration of solar energy systems with traditional plants is the most satisfactory solution: as presented in paragraph 2.3.1, even if they do not reach the production levels of the technologies powered by conventional sources, they can produce up to a hundred daily cubic meters at a cost that would allow them to be used.

\section{SDGC system}

The SDGC process (Solar Desalination Geoassisted Continuous) is an innovative thermal distillation process that is essentially based on a first humidification phase and a second phase of air dehumidification, exploiting, at steady state, only solar thermal energy. As explained below, the development of this process is based on achieving a condition of equilibrium in which the only energy necessary for the system is provided to compensate for the inevitable inefficiencies, thus allowing the process of self-maintenance for a sufficiently long time to justify its industrial use.

The patented invention SDGC refers to a method, and to a device for implementing the said method, to desalinize sea water, brackish water or from industrial processes, in a continuous and self-supported mode. In particular, the device according to the invention is suitable to use renewable energy sources, by means of solar energy and geothermal energy.

The object of the invention is to propose a method and a device for the implementation of the said method for the desalting, using renewable sources (thermal and electric solar, geothermal, photovoltaic or wind) and in regimes of moderate temperatures, taking into high consideration the management and handling of the concerned energy quantities, inside an essentially adiabatic system, with the possibility to compensate the phase shifts between the energy needs and the natural availability, in giving or in having, at particular time, by resorting to the sun or subsoil or wind, depending on the necessity.

The method is of the type which expects to cause the evaporation of said water to desalinate, the subsequent condensation of the steam and the collection of the condensed water, characterized by:

- working in a closed tank in which the water to desalinate and the water vapor resulting from evaporation of said water are simultaneously present; 
Asian Journal of Applied Science and Technology

Volume 4, Issue 3, Pages 183-209, July-September 2020

- heating said water to desalinate in the nearness of the surface of said water, so that said surface and said produced steam are at a higher temperature than the temperature present in the depth of the water to desalinate;

- causing the condensation of said steam and to collect the condensed water, said condensation taking place on cooling means, which are in heat exchange connection with the heating means, immersed in said water to desalinate, said heat exchange simultaneously causing:

a) the reduction of temperature of said cooling means, then the suitable conditions for the condensation of the steam;

b) the increase of temperature, in depth, of said water to desalinize.

The device is of the type that includes a tank for the containment of the water to desalinize, in which there are heating means fitted to cause the evaporation of said water to desalinize, cooling means fitted to favour the subsequent condensation of the steam and means fitted to the collection of the condensed water, characterized in that:

- said tank, fitted to contain said water to desalinize, is filled up to a certain level, so as to present a free surface of the water;

- said heating means, fitted to cause the evaporation of said water to desalinate, include a first heat exchanger, immersed in the water to desalinate and positioned in the nearness of said free surface;

- said cooling means, fitted to cause the condensation of the steam, are in heat exchange connection with the heating means, immersed in said water to desalinate, said heat exchange simultaneously causing:

a) the reduction of the temperature of said cooling means, therefore the suitable conditions for the condensation of the steam;

b) the increase in temperature, into the depths, of said water to desalinate;

- conveying means fitted to collect the condensed water on said cooling means.

They are provided two heat exchangers arranged vertically, at both outer sides of the upper half of the liquid phase; they will be able to support the standstill processes, if any, or next to regimes of uniform entropy in the space bounded by the main tank, locally lowering the temperature of the surrounding water which, due to the higher density, reintroduces the convective motions.

The use of a device in compliance with the invention allows the production, at very low operating costs, of fresh water for multiple uses: plant engineering and food industry, agronomy, animal husbandry, and finally also for the human use.

The use of a device in compliance with the invention also allows significant contributions in the remediation and purification actions of water bodies from industrial processes that weigh on the rural and urban territories, where the human action has reached critical levels that natural processes cannot face. 


\subsection{Detailed description}

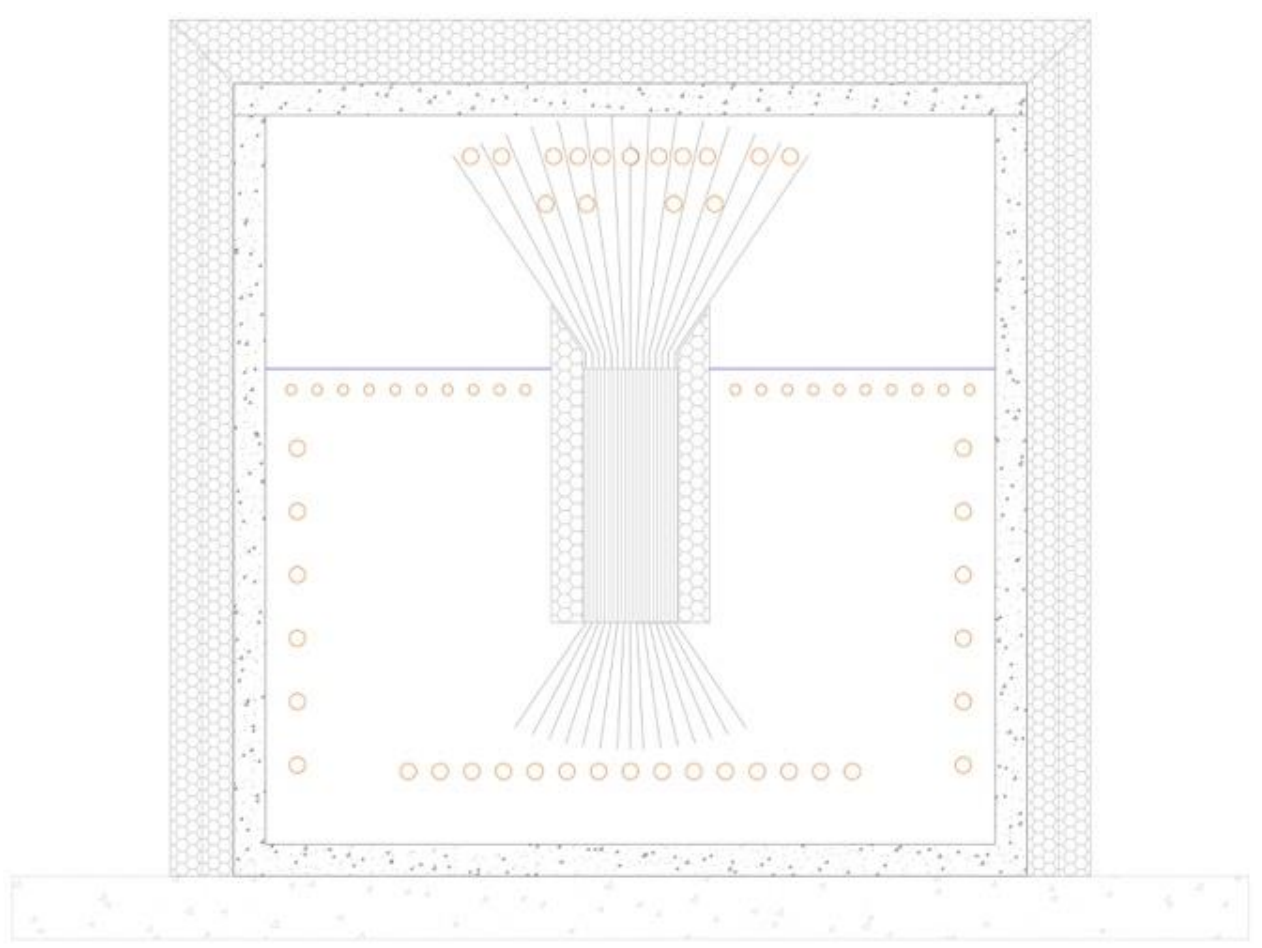

Fig.8 SDGC system layout

\subsubsection{System structure}

The system is made up of a reinforced concrete tank in the shape of a parallelepiped, thermally insulated by polyurethane foam panels to give it adiabatic characteristics, the inside of which is filled to about two thirds of the volume with the salt water to be treated. In correspondence with the free surface of the plant, the tank is crossed by a series of corrugated pipes, made of materials characterized by a high thermal conductivity and connected to the system that will provide the main thermal energy and maintenance energy that will heat the salt water and maintain it at the established regimes.

Other corrugated pipes of the same material run through the tank at the top, bottom and side of the system; as will be explained below, these take on the function of reserve heat exchangers, able to intervene if a thermal equilibrium condition is reached in the system which, as will be explained in the following sections, represents a critical feature of the plant operation.

The whole tank is longitudinally crossed by a set of pressed sheets made of a material which is very thermally conductive and has an appropriate size and a predetermined percentage of vacuum / solid, such as to optimize the need for a sufficiently extended heat exchange surface while not hindering the movement of air. These plates are installed vertically in the central part of the tank, while they open to an accordion-like structure in the upper and lower part (Figure 8).

Near the free surface and up to a certain depth in the salt water, defined according to the temperature gradient between the free surface and the bottom of the tank so that the lower part is in contact with the coldest salt water, 


\section{AJAST}

Asian Journal of Applied Science and Technology

Volume 4, Issue 3, Pages 183-209, July-September 2020

these sheets are compacted and thermally insulated with respect to the portion of water heated by the main heat exchanger, and the interstices formed by the reciprocal tiling are filled with liquid aluminum.

This structure, called the thermal tunnel (Figure 8), represents a channel of communication between the two parts of the plant bordering a common area heated to a different temperature and, as explained in the following paragraphs, represents also the fulcrum of the whole system (Lavanga \& Farné, Sistema di dissalatore geoassistito continuo, Patent 2016).

In order to allow the process to develop with sufficient industrial speed, the whole tank is kept depressurised at predetermined levels and a suitable stirring system allows air to be supplied at the required speed in the portion of the tank not filled with salt water.

\subsubsection{Working at full capacity}

The operating principle is based on the heating of the salt water next to the free surface, while the water at the bottom remains at a lower temperature. During steady state operation, the free surface of the salt water is maintained at an average temperature of approximately $55-60{ }^{\circ} \mathrm{C}$ by the solar thermal system, while the temperature at the bottom remains at around $15-25^{\circ} \mathrm{C}$ (the temperature of the water entering the tank). This transversal temperature gradient recalls the operating principle of stratified accumulation systems used in plumbing and heating systems and is of fundamental importance for the functioning of our system, because it represents the real "engine" of the system. The point of entry of thermal energy is not random; in fact, the heating system delivery is located in the central part of the system, while the return is positioned near the walls of the tank. All this makes it possible to obtain a non-homogeneous temperature distribution at the free surface and this promotes the priming and maintenance of the rotary convective motions.

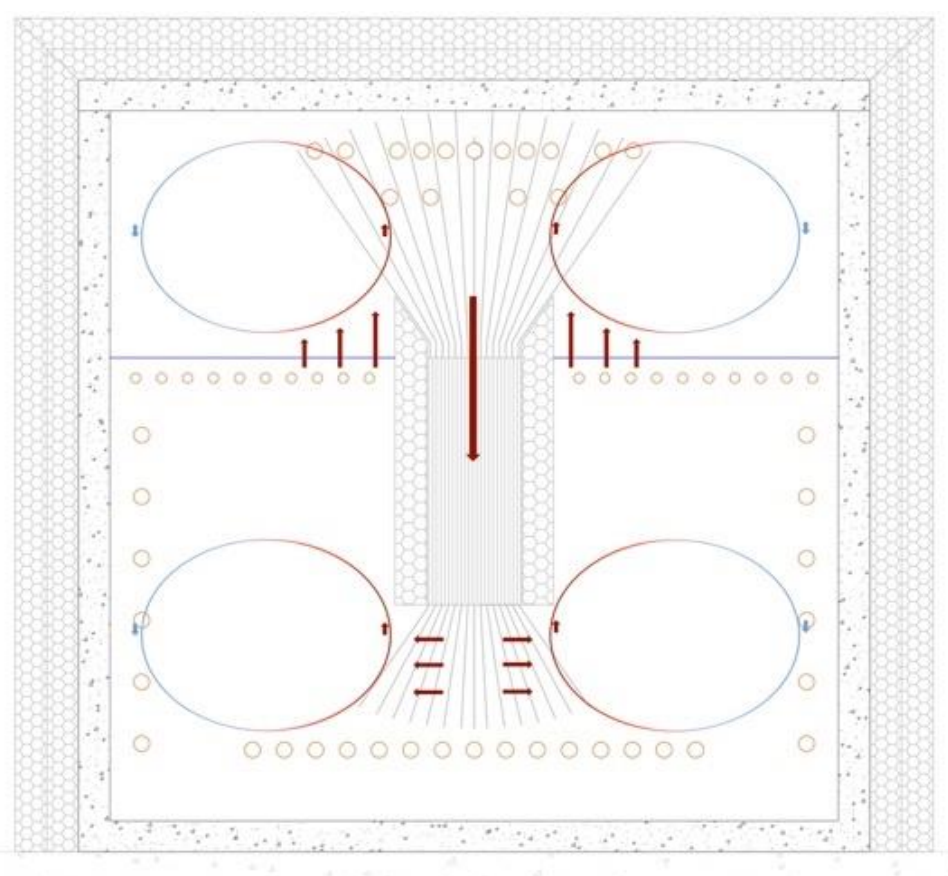

Fig.9 Convective motions and energy flows in the SDGC system 
On the free surface of the tank, an evaporation process begins which, unlike boiling, has a lower speed and affects only the free surface of a fluid mass, as well as being visible at any temperature. Together with evaporation, on the free surface there is also a transfer of heat from the water to the air that allows the triggering of convective motions, promoted by the agitation system inside the tank. The greatest evaporation occurs near the central part of the system, due to the higher delivery temperature and, thanks to this, the air is charged with humidity. Furthermore, the vacuum setting of the tank further increases the evaporated flow rate.

The heated and humidified air, pushed upwards by convective motions and by the stirring system, comes into contact with the pressed metal sheets of the accordion structure. The latter, being in direct contact with the colder water at the bottom of the tank, are characterized by a lower temperature than the humidity of the humid air, so that in this phase the dehumidification process takes place by condensation of the steam in contact with the metal sheets. The condensate percolates on the pressed metal sheets up to a collection channel, to then be sent outside the plant. In this phase the humid air gives heat to the sheets, which also includes the latent heat of condensation. Thanks to the thermal gradient between the upper part of the sheets, which is warmer due to dehumidification, and the lower part immersed in cold salty water, the absorbed heat is conveyed towards the lower part of the system through the thermal tunnel, where it is transmitted to the salt water and then completely recovered.

Figure 9 shows the convective motions and the energy flows involved in the system. As for the humidified air, as this gives up heat during the condensation phase, and its temperature continues to decrease to the point where it has reached a condition that causes it to move downwards. Considering the submerged portion of the system, also in this area convective motions are formed. The heat given off by the sheets, in fact, heats the water at the bottom of the tank, which, thanks to the different density, rises back to the free surface, producing convective motions. From this, the efficiency of the system is evident; in fact, unlike conventional systems, thanks to the maintenance of temperature gradients and the vacuum at the preset values, by supplying the initial thermal energy at the start of the process, the plant is able to sustain itself autonomously through the total recovery of latent condensation heat, integrating only the energy necessary to compensate for losses through the enclosure (Lavanga \& Farné, Sistema di dissalatore geoassistito continuo, Patent 2016).

\subsection{Mathematical model of the process}

The mathematical model that allows the analysis of the process and its design is presented below. The analysis was performed by decomposing the system and modelling the individual processes that occur during normal operation.

\subsubsection{Evaporated flow rate}

The evaporated flow rate from the free surface of the tank can be modelled through the convective diffusion equations. By definition, in the contact zone between a liquid and its own vapor, the saturation pressure applies, so the hygrometric degree (or relative humidity if expressed as a percentage, indicated below with the symbol " $\phi$ ") expressed as the ratio between the partial pressure of water vapor $p_{v a p}$ and the saturation pressure of water at a given temperature $p_{v}$, is 1 . This value will be constant throughout the system, since for operation it is not necessary to change the percentage of relative humidity in the air, but only the amount of water present. We call: 
- $\quad p_{\text {vap } 0}:$ partial pressure of water vapor on the free surface;

- $\quad p_{v a p L}$ : partial pressure of the water vapor at such a distance as not to be disturbed by the effects that occur on the free surface (in the system, this is the top of the tank);

- $\quad p_{v}(T)$ : saturation pressure at temperature $\mathrm{T}$ (expressed in ${ }^{\circ} \mathrm{C}$ or $K$, according to the calculation system or the table used to derive it).

As stated above, we can reasonably assume that the vapor pressure on the free surface is equal to the saturation pressure measured at the water temperature on the free surface, while the vapor pressure near the top of the tank will be equal to the saturation pressure evaluated at the dehumidified air temperature, since the hygrometric degree is everywhere unitary:

$$
\begin{aligned}
& p_{\text {vap } 0}=p_{v}\left(T_{0}\right) \\
& p_{\text {vapL }}=p_{v}\left(T_{L}\right)
\end{aligned}
$$

The water vapor spreads upwards with a partial pressure that decreases as the distance from the free surface increases. Diffusion is a phenomenon that manifests itself in space; however, we neglect the diffusion of water vapor downwards (when blocked by the presence of water) and towards the side walls (the vapor permeability of the walls is assumed to be negligible), to consider the one-dimensional vapor flow upwards (i.e. from the free surface of the tank towards the roof).

On this premise, we can take advantage of the generalized Fick's Law (Farina, Santi \& Lavacchielli, 2014, chapter 3 , p. 4), with which one can express the molar flow of vapor per unit of surface that spreads in air:

$$
\vec{N}_{A}=-C D_{A B} \cdot \operatorname{grad}\left(x_{A}\right)+x_{A} \vec{N}_{A} \quad\left[\frac{k m o l}{m^{2} s}\right]
$$

in which the first of the two addenda quantifies the phenomenon of diffusion, while the second one is transport of the matter. For the hypothesis about the directionality of the flow, we can simplify the relation in the case of one-dimensional flow:

$$
N_{A_{z}}=-C D_{A B} \frac{d x_{A}}{d z}+x_{A} N_{A_{z}} \quad\left[\frac{k m o l}{m^{2} s}\right]
$$

Where:

- $\quad N_{A_{z}}\left[\mathrm{kmol} / \mathrm{m}^{2} \mathrm{~s}\right]:$ molar flow of water;

- $\quad C\left[\mathrm{kmol} / \mathrm{m}^{3}\right]$ : concentration of the chemical species;

- $D_{A B}\left[\mathrm{~m}^{2} / \mathrm{s}\right]$ : binary diffusivity of water in air, evaluated at the water temperature on the free surface;

- $\quad x_{A}[$ adim] $:$ molar fraction of the chemical species A (water vapor).

Explicating, we get: 


$$
N_{A_{Z}} d z=-C D_{A B} \frac{d x_{A}}{1-x_{A}} \quad\left[\frac{k m o l}{m s}\right]
$$

and integrating formula (2) along the whole length of interest $z$ results in:

$$
N_{A_{z}} \int_{0}^{L} d z=-C D_{A B} \int_{x_{A_{0}}}^{x_{A_{L}}} \frac{d x_{A}}{1-x_{A}} \quad N_{A_{z}} L=C D_{A B} \ln \left(\frac{1-x_{\text {vap } L}}{1-x_{\text {vap } 0}}\right) \quad\left[\frac{\mathrm{kmol}}{\mathrm{ms}}\right]
$$

$a$

$b$

in which $L$ indicates the distance between the free surface and the tank cover. Recalling that, from Dalton's partial pressures law (that is, that the total pressure exerted by an ideal mixture of ideal gases is equal to the sum of the partial pressures that would be exerted by the gases if they were present alone in an equal volume), we have that $x_{a s}+x_{v a p}=1$, the formulation becomes:

$$
N_{A_{z}} L=C D_{A B} \ln \left(\frac{x_{a s L}}{x_{a s 0}}\right) \quad\left[\frac{k m o l}{m s}\right]
$$

Assuming that both aeriforms (water vapor and dry air) behave like perfect gases, the following relationships can be applied:

$$
\begin{array}{ccc}
x_{A}=\frac{p_{A}}{p_{\text {tot }}} & x_{a s}=\frac{p_{a s}}{p_{\text {tot }}} & C=\frac{p_{\text {tot }}}{R T} \\
a & b & c
\end{array}
$$

Substituting in formula (5) and applying to our system, we obtain:

$$
N_{A_{z}}=\frac{p_{t o t} D_{A B}}{R T L} \ln \left(\frac{p_{t o t}-\phi p_{s a t}\left(T_{L}\right)}{p_{\text {tot }}-\phi p_{s a t}\left(T_{0}\right)}\right) \quad\left[\frac{\mathrm{kmol}}{\mathrm{m}^{2} \mathrm{~s}}\right]
$$

As stated at the beginning of the paragraph regarding the psychrometric state of the moist air inside the tank, the relationship (7) becomes:

$$
N_{A_{z}}=\frac{p_{t o t} D_{A B}}{R T L} \ln \left(\frac{p_{t o t}-p_{\text {sat }}\left(T_{L}\right)}{p_{\text {tot }}-p_{\text {sat }}\left(T_{0}\right)}\right) \quad\left[\frac{\mathrm{kmol}}{\mathrm{m}^{2} \mathrm{~s}}\right]
$$

in which $R$ is the universal constant of the perfect gases, while $T$ represents the average temperature between the one near the covering and the one at the free surface of the tank, corresponding to a medium concentration. As will be seen in the following, this approximation will be irrelevant in the calculations. From formulas (7) and (8), it can be seen how, in the case of an environment in saturation conditions (relative humidity equal to $100 \%$ or unit hygrometric degree), the evaporation speed depends essentially on the total pressure and the process temperatures which, influencing the saturation conditions, are fundamental for the good functioning of the plant. 
Expressing the result in terms of mass flow and not of molar flow, the evaporated mass flow per unit of surface is obtained (Farina et al., 2014, chapter 7, p. 4):

$$
\dot{\mathrm{m}}_{\mathrm{H}_{2} \mathrm{O}}=N_{A_{z}} \mu_{\mathrm{H}_{2} \mathrm{O}} \quad\left[\frac{\mathrm{kg}}{\mathrm{m}^{2} \mathrm{~S}}\right]
$$

in which $\mu_{\mathrm{H}_{2} \mathrm{O}}=18 \mathrm{~kg} / \mathrm{kmol}$ is the molar mass of water.

Analyzing the problem from the engineering point of view, we realize that in this type of equation the speed of the air inside the tank is not considered, which is a fundamental element for increasing the potential of the system. Therefore, stopping at this level of analysis would lead to poor results, because it is implicitly affirming that the air above the tank is stopped.

To increase the level of detail, we rely on the relations of technical physics, and in particular the analogy that exists between the heat exchange by convection and the exchange of matter by diffusion. Comparing the equations that regulate these exchanges, in fact, it is possible to find a correspondence between the heat exchange by convection, expressed through Fourier's law (as in Moran, Shapiro, Munson, \& DeWitt, 2011. P. 466) and the exchange of matter between chemical species, regulated by Fick's law (Farina et al., 2014, chapter 4). At an engineering level, when equations and physical laws are elaborated, we often try to compact them according to the "single number" rule; in other words, we try to create a relationship between two quantities through a coefficient. In the case of heat exchange, to process the Fourier equation, the single number widely used is the convection coefficient $h$, from which Newton's law derives (Moran, Shapiro, Munson, DeWitt, 2011, p. 468):

$$
P=\bar{h}\left(T_{p}-T_{\text {inf }}\right) \quad\left[\frac{W}{m^{2}}\right]
$$

in which:

- $\quad \bar{h}\left[W / m^{2} K\right]:$ average value of the convection coefficient on the surface;

- $\quad P\left[W / m^{2}\right]$ : intensity of the specific heat flow;

- $T_{p}[K]$ : contact temperature with the wall;

- $\quad T_{\text {inf }}[K]$ : temperature at a distance such that the effects due to the presence of the wall are not felt.

In reality, the convective coefficient varies according to the temperature difference, so the link between the power and the temperature difference is not linear. However, for common engineering problems a convective coefficient can be considered as averaged over a characteristic length and considering their linear link without making significant errors (Moran et al., 2014, p. 562).

Taking advantage of the analogy, one can express the law of convective diffusion in a similar way:

$$
n_{A}=\bar{h}_{m}\left(\rho_{A_{p}}-\rho_{A_{\text {inf }}}\right) \quad\left[\frac{\mathrm{kg}}{\mathrm{m}^{2} \mathrm{~s}}\right]
$$


in which:

- $\quad n_{A}\left[\mathrm{~kg} / \mathrm{m}^{2} \mathrm{~s}\right]$ : flux intensity of the chemical species A (water);

- $\quad \rho_{A_{p}}\left[\mathrm{~kg} / \mathrm{m}^{3}\right]$ : density of species A on the wall;

- $\quad \rho_{A_{\text {inf }}}\left[\mathrm{kg} / \mathrm{m}^{3}\right]$ : density of species A at a distance such that the effects due to the presence of the wall are not felt;

- $\quad \bar{h}_{m}\left[\mathrm{~W} / \mathrm{m}^{2} \mathrm{~K}\right]:$ average transport coefficient of matter in the diffusive field.

Like the previous one, this too is not a linear relation since the material transport coefficient is not an absolute constant.

Applying the equation to the model and exploiting the relation (9) and the equation of perfect gases, we can obtain:

$$
\dot{m}_{\mathrm{H}_{2} \mathrm{O}}=\frac{\bar{h}_{m} \mu_{\mathrm{H}_{2} \mathrm{O}}}{R}\left(\frac{p_{\text {vapo }}}{T_{0}}-\frac{p_{\text {vapinf }}}{T_{\text {inf }}}\right) \quad\left[\frac{k g}{\mathrm{~m}^{2} \mathrm{~S}}\right]
$$

In order to determine the flow rate of evaporated water per surface unit, the coefficient of exchange of matter in the diffusion field must be determined. The thermal-diffusive analogy allows the problem to be approached analogously to the heat exchange, so it is possible to determine it by using some dimensionless numbers. The first non-dimensional number needed is the Reynolds number, expressed as (Farina et al., 2014, chapter 4, p. 10):

$$
\left.R e_{L_{c}}=\frac{v_{\text {inf }} L_{c}}{v\left(T_{\text {inf }}\right)} \quad \text { [adim. }\right]
$$

This expresses the relationship between the forces of inertia and the viscous forces, and its items are:

- $\quad v_{\text {inf }}[\mathrm{m} / \mathrm{s}]$ : fluid speed;

- $\quad L_{c}[m]:$ characteristic size;

- $v\left(T_{\text {inf }}\right)\left[\mathrm{m}^{2} / \mathrm{s}\right]$ : kinematic viscosity at the temperature of the undisturbed current.

The Reynolds number is necessary to establish whether the process of convective diffusion takes place in a laminar or turbulent regime. From the literature, limiting the analysis to our process (approximated in these terms as a flat plate lapped by a moving fluid), the critical Reynolds number for which the transition from laminar to turbulent flow is considered is equal to 500,000, which is much greater than the transition value for cases of fluid flowing inside a pipe.

The second dimensionless number necessary for the analysis is the Schmidt number, expressed as (Farina et al., 2014, chapter 4, p. 11):

$$
S c=\frac{v\left(T_{\text {inf }}\right)}{D_{A B}}
$$

This expresses the relationship between the kinematic diffusivity and the diffusivity of matter and, compared to the thermal-diffusive analogy, is the equivalent of the Prandtl number. These items have already been explained in the 
Asian Journal of Applied Science and Technology

Volume 4, Issue 3, Pages 183-209, July-September 2020

previous pages. The last non-dimensional number needed for the calculation is the Sherwood number, expressed as (Farina et al., 2014, chapter 4, p. 11):

$$
\overline{S h}_{L_{c}}=\frac{\bar{h}_{m} L_{c}}{D_{A B}}
$$

This represents the relationship between the convective and diffusive mass transfer and is the analog of the Nusselt number in the diffusive field. Equivalently to this, it is possible to express the Sherwood number according to the Reynolds and Schmidt numbers raised to appropriate coefficients, through Colburn's reports (Farina et al., 2014, chapter 6, p. 11).

Leaving to the literature the treatment of these relationships, there are only two that are of practical interest for the system under examination, one related to the laminar regime, the other relative to the turbulent one; the use of one or the other equation depends on the value of the Reynolds number, as stated on the previous page:

Laminar

$$
\overline{S h}_{L_{c}}=0.664 R e_{L_{c}}^{1 / 2} S c^{1 / 3}
$$

$a$
Turbulent

$$
\overline{S h}_{L_{c}}=\left(0.037 R e_{L_{c}}^{4 / 5}-871\right) S c^{1 / 3}
$$

By obtaining the average convection coefficient through the dimensionless numbers, it is possible to easily calculate the evaporated flow per unit of surface according to formula (12) and, subsequently, to obtain the flow evaporated from the entire free surface of the tank through formula (12) (Farina et al., 2014).

\subsubsection{Required power}

In steady-state operation, the salt water temperature inside the tank is already at the process value. Therefore, as explained in the previous pages, the only thermal power to be introduced is that needed to overcome the losses through the casing. In this regard, it is necessary to proceed considering that there are two fluids that interact with the heat exchange through the insulated walls of the tank.

The part of the tank submerged by salt water will, in fact, contribute to the losses in a different way from the portion in the air. Moreover, during the design, the installation position of the tank (underground, basement or external) must be taken into account in relation to the different materials that will contribute or not to the losses.

The specifics of the calculations will be presented in the following sections, while the following is the commonly adopted formula that allows us to calculate the losses through a stratigraphy (Moran et al., 2011, p. 495):

$$
P_{\text {tot }}=\sum_{i=1}^{n} P_{i}
$$

where $P_{i}$ indicates the i-loss contributions determined by the different conditions inside and outside the tank exposed above, calculated as: 


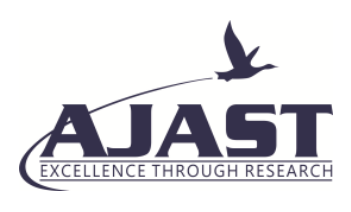

Asian Journal of Applied Science and Technology

Volume 4, Issue 3, Pages 183-209, July-September 2020

$$
P_{i}=U_{i} A_{i} \Delta T_{i}
$$

where the items are:

- $\Delta T_{i}[K]$ : difference between the internal and external temperature related to the loss surface considered;

- $\quad A_{i}\left[m^{2}\right]$ : loss surface considered;

- $\quad U_{i}\left[\mathrm{~W} / \mathrm{m}^{2} \mathrm{~K}\right]$ : thermal transmittance of the stratigraphy related to the loss surface considered, evaluated on the basis of the standards UNI EN ISO 6946:2008 (Components and building elements - Thermal resistance and thermal transmittance - Calculation method) and UNI EN ISO 13370:2008 (Thermal performance of buildings - Heat transfer through the ground - Calculation methods).

If the envelope of the system is properly thermally insulated, this contribution can be very small (Moran et al., 2011).

\subsubsection{Distillate production}

For the evaluation of the amount of distillate produced, it is necessary to consider that, when operating and in the best operating conditions, the maximum condensable quantity is strongly dependent on the quantity of evaporated water and in any case it cannot condense more than the system is managing to evaporate (otherwise it means that the plant is "creating" water, which is obviously absurd). The water vapor contained in the humidified air starts to condense as soon as it finds a surface with a temperature equal to or lower than its dew temperature, and this complicates the analysis of the model. As a first approximation, it is assumed that steam starts to condense only once the thermal equilibrium between water and steam has been reached (this means at the limit of the stopping of the evaporative phase, as reported in formula (12)); this is a very strong approximation but, while still awaiting real measurements, allows us to obtain a good result. Under this hypothesis, through the diagrams or psychrometric calculators, we obtain the thermo-hygrometric values related to the initial and final conditions of the condensation phase. The specific value of condensed water is obtained through the following formula (Moran et al., 2011, p. 321):

$$
\dot{m}_{H_{2} O_{u}}=\omega_{2}-\omega_{1} \quad\left[\frac{k g_{v}}{k g_{a s}}\right]
$$

in which the items represent:

- $\quad \omega_{2}\left[\mathrm{~kg}_{v a p} / \mathrm{kg}_{a s}\right]:$ specific humidity of the humidified air;

- $\omega_{1}\left[\mathrm{kgap}_{v a \mathrm{p}} / \mathrm{kg}_{\mathrm{as}}\right]$ : specific humidity of dehumidified air.

This value is necessary to calculate the flow of dry air, which in turn is necessary to determine the power developed during condensation and to size the exchange surface.

Under the previous hypotheses, therefore, the flow of dry air is evaluated with the following formula (Moran et al., 2011, p. 320): 


$$
\dot{m}_{a s}=\frac{\dot{m}_{\mathrm{H}_{2} \mathrm{O}}}{\dot{m}_{\mathrm{H}_{2} \mathrm{O}}}=\frac{\dot{m}_{\mathrm{H}_{2} \mathrm{O}}}{\omega_{2}-\omega_{1}} \quad\left[\frac{\mathrm{kg}}{\mathrm{s}}\right]
$$

Subscripts " 1 " and " 2 " indicate the conditions of the humid air and must not be misunderstood; even if it represents the final state of the dehumidification phase, it has been decided to indicate with subscript " 1 " the dehumidified air because it corresponds to the initial condition before the humidification.

From the flow of dry air, through the well-known formula deriving from technical physics (Moran et al., 2011, $\mathrm{p}$ 320), it is possible to obtain the mass flow of humid air to be moved with the stirring system:

$$
\dot{m}_{a u}=\frac{\dot{m}_{a s} R_{i} T_{a u}}{p_{a s}} \quad\left[\frac{k g}{s}\right]
$$

in which:

- $\quad \dot{m}_{a s}[\mathrm{~kg} / \mathrm{s}]:$ mass flow of dry air;

- $\quad p_{a s}[P a]:$ partial pressure of dry air;

- $\quad R_{i}[J / \mathrm{kgK}]$ : specific constant of dry air, equal to $287[\mathrm{~J} / \mathrm{kgK}]$;

- $T_{a u}[K]$ : temperature of the moist air mixture.

Formulas are taken from (Moran et al., 2011).

\subsubsection{Thermal tunnel}

The model for calculating the thermal tunnel consists in evaluating the number of pressed sheets necessary for the system to produce the maximum quantity of condensate, corresponding to the quantity of evaporating water under certain operating conditions. The base of the thermal tunnel is an area characterized by a high thermal conductivity, due to the flanking of all the expanded metal sheets. Having this characteristic, if placed in contact with the colder area of the plant (the water at the bottom of the tank), it can reasonably be deduced that its temperature, during normal operation, will not be very different from that at the bottom of the tank and, above all, it will remain constant during operation. From this, we can think of the base of the thermal tunnel as a surface that must absorb a large quantity of thermal energy and, from the technical physics rules (Moran et al., 2011, p. 511), the expanded metal sheets can be seen as a finned surface which must promote such absorption. Therefore, we use the analysis models of the finned surfaces to evaluate the number of fins necessary to allow heat exchange. The expanded metal sheets are produced in sheets of standard dimensions and the geometrical characteristics of interest for the calculation are:

- Commercial dimensions of the sheet $[m]$ and its surface $\left[\mathrm{m}^{2}\right]$;

- Percentage value of the void on full $[\mathrm{m}]$ : this represents the percentage of perforated surface compared to the metallic one and can vary widely. As will be seen in the following sections, it is of fundamental importance for the success of the design.

As the literature teaches, the fins are generally continuous surfaces of conductive material. Therefore, in order to bring us back to the model, it is necessary to obtain the equivalent metallic surface of the pressed sheets, since it 
will only be that which carries out the heat exchange. Taking advantage of the data available, this is obtained with the following formula:

$$
S_{l s_{e q}}=S_{l s}\left(1-\frac{\% V P}{1-\% V P}\right) \quad\left[m^{2}\right]
$$

in which:

- $\quad S_{l s}\left[m^{2}\right]$ : commercial surface of expanded metal;

- $\quad \% V P[\%]$ : percentage value of void on full.

Through the equivalent metal surface, the geometry of the sheet metal pre-stretching is obtained, with which the number of fins (pressed sheets) is calculated, so that the heat exchange takes place.

From the literature, we know that the analysis of the fins is regulated by the calculation of some coefficients that allow a simplification of the calculations.

As regards their theoretical treatment, refer to the bibliography (Moran et al., 2011; Magrini \& Magnani, 2009).

The "M" coefficient of the fin (Magrini \& Magnani, 2009, p. 255) is as follows:

$$
m=\sqrt{\frac{2 h}{\lambda s}} \quad\left[m^{-1}\right]
$$

where:

- $\quad h\left[W / m^{2} K\right]:$ convective coefficient;

- $\lambda[W / m K]:$ thermal conductivity of the material constituting the expanded metal sheets;

- $s[m]$ : thickness of pressed sheets.

The coefficients "A" and "B" of the fin (Magrini \& Magnani, 2009, p. 255) are:

$$
A=\frac{t_{p}-t_{a m b}}{1+\frac{\lambda m-h}{\lambda m+h} e^{-2 m H_{l s}}} \quad B=\frac{t_{p}-t_{a m b}}{1+\frac{\lambda m+h}{\lambda m-h} e^{2 m H_{l s}}}
$$

$a$

\section{$b$}

with $H_{l s}$ the height of the expanded metal, expressed in meters.

Once the coefficients have been defined, the unit thermal flow is evaluated through the single stretched sheet (Magrini \& Magnani, 2009, p. 255):

$$
P_{u}=-\lambda s l_{e q}(B-A) m \quad\left[\frac{W}{f i n}\right]
$$

in which $l_{e q}$ is the equivalent length of the expanded metal. 
To estimate the number of sheets, it is necessary to calculate the total thermal power absorbed by the sheets stretched during the condensation, obtainable by means of an energy balance such as (Moran et al., 2011, p. 329):

$$
P=\dot{m}_{a s}\left(\left(H_{a u_{d}}-H_{a u_{u}}\right)+\left(\omega_{2}-\omega_{1}\right) H_{H_{2} O}\right)
$$

whose items not already explained in the previous paragraphs are:

- $H_{a u_{d}}[\mathrm{~kJ} / \mathrm{kg}]:$ enthalpy of humid air, dehumidified;

- $\quad H_{a u_{u}}[k J / k g]$ : enthalpy of humid air, humidified;

- $H_{H_{2} O}[k J / k g]:$ enthalpy of the condensate, treated as saturated liquid.

All enthalpy values can be obtained from the tables showing the properties of the air.

Having calculated the total power required for condensation, we calculate the number of fins necessary for thermal exchange to take place:

$$
n_{\text {fins }}=\frac{P}{P_{u}} \quad[\text { fins }]
$$

The number of fins must be appropriately placed at the base of the thermal tunnel considering the total size of the metal sheet, not the equivalent one used for the calculation.

\section{Conclusions}

This paper has presented the first phase of the development of the Solar Desalination Geoassisted Continuous system, a new and innovative type of system for desalinating marine or brackish waters through a rational use of energy. In the first part of the paper, the most widespread techniques used to date for the desalination of salty and brackish waters have been recalled, showing that almost all of them are operating using a large amount of energy obtained by conventional sources to satisfy all or part of the requirement. In the following part of the paper, some of the technologies that aim at a massive use of renewable sources have been presented, but they are today not very practicable due to the system complexity in relation to the low producibility in terms of desalinated water.

In the second part of the paper, the SDGC system was introduced, presenting the theoretical settings and the operating principles. The mathematical model make it possible to relate the geometrical and thermophysical parameters to the operating conditions of the plant, allowing an easy-to-use formulation to be obtained for calculating the producibility of the plant. The main innovative aspect of the system consists in reproducing, in a restricted environment, the water cycle that commonly occurs in nature. In fact, through the solar thermal energy, part of the water present in the seas and oceans evaporates according to the relationship presented in paragraph 2.2, returning towards the atmosphere.

Thanks to the convective motions, the mass of water in the aeriform state is pushed up to an environment in which it condenses, due to the low pressures and temperatures, precipitating later to the ground. The SDGC system exploits and accelerates this process: solar energy is used to heat the heat-carrying fluid which, by means of a heat 
Asian Journal of Applied Science and Technology Volume 4, Issue 3, Pages 183-209, July-September 2020

exchanger, heats the surface of the mass of water present in the tank, making it evaporate in a closed environment in vacuum and with artificially accelerated moist air. All this allows a faster process and the almost total recovery of latent heat thanks to the presence of the thermal tunnel.

The operation of the system allows the recovery and continuous reuse of the latent heat, making the SDGC a practically self-supplying system, since the thermal energy supplied during the start-up phase is continuously reused thanks to the presence of the thermal tunnel, unless lost through the envelope, which is reintegrated through solar collectors. This element represents the heart of the whole system and, at the same time, its most critical part. In fact, it plays a dual role of equal importance: acting as a condensation and condensate collection surface and at the same time recovering the latent heat to reuse it within the system itself, allowing it to self-feed. This second function is implemented by realizing a communication path between the condensation zone and the exchange zone at the bottom of the tank, passing through the portion of water heated to the free surface.

This solution actually represents a great innovation, since it allows the complete recovery of the latent heat to feed the main process and not, as often happens in traditional systems, for secondary pre-heating functions. This allows a remarkable reduction of the energy to be supplied to the system and, consequently, the related costs. In a future paper, based on the mathematical model, it will be presented a preliminary sizing of the most important parts, assessing any critical operating conditions and preparing the most suitable means to counteract them. In this development phase, particular attention will be paid to the standardization of the system, choosing to assemble elements commonly available in the industrial sector, paying more attention to the functionality and effectiveness of the element and leaving the system optimization for future developments.

\section{Acknowledgments}

Dr. Vito Lavanga, freelance researcher and inventor.

\section{Patents}

Farné Stefano - Lavanga Vito - Method for the Continuous Desalinization and Device for the Implementation of Said Method.

Publication Number WO/2016/162896 - Publication Date 13.10.2016

SDGC https://patentscope.wipo.int/search/en/detail.jsf?docId=WO2016162896 (sea and process water solar desalination)

\footnotetext{
References

Ayoub, G.M., \& Malaeb, L. (2014) Economic feasibility of a solar still desalination system with enhanced productivity, Desalination, Vol. 335, No. 1, pp.27-32.

Bacha, B.H. (2013) Dynamic modeling and experimental validation of a water desalination prototype by solar energy using humidification-dehumidification process, Desalination, Vol. 332, pp.182-208.

Battisti, R. (2013) Impianti solari termici per reti di teleriscaldamento, Dario Flaccovio, Palermo.

Calza, F. (2010) Manuale degli impianti termici e idrici, Tecniche Nuove, Milano.
} 
Asian Journal of Applied Science and Technology Volume 4, Issue 3, Pages 183-209, July-September 2020

Cervinia, V.M., Masaki, O., Tetsuji, O., Satoshi, N., \& Wataru, N. (2016) Effect of biofilm on inorganic suspended solids accumulation on reverse osmosis membranes, Japan Society On Water Environment, Vol. 14, No. 5, pp.308-318.

Chang, Z., Zheng, H., Yang, Y., Su, Y., \& Duan, Z. (2014) Experimental investigation of a novel multi-effect solar desalination system based on humidification-dehumidification process, Renewable Energy, Vol. 69, pp.253-259.

Cipollina, A., Micale, G., Rizzuti, L (Eds.) (2009) Seawater Desalination: Conventional and renewable energy processes, Springer, New York.

de la Cruz, L., Cynthia, L. (2015) Studio di fattibilità di un impianto di dissalazione ad osmosi inversa con l'utilizzo di energia solare fotovoltaica, Politecnico di Milano, Milano.

Ducci, C. (2012) Studio e dimensionamento di un sistema per la dissalazione e la generazione di energia con accumulo in aree rurali isolate, Padova Digital University Archive, Padova.

El-Agouz, S.A., Abd El-Aziz, G.B., \& Awad, A.M. (2014) Solar desalination system using spray evaporation, Energy, Vol. 76, pp.276-283.

Farina, A., Santi, A., \& Lavacchielli, G. (2014) Termofluidodinamica applicata, Università degli studi di Parma, Parma.

Farnè S., Lavanga V., Giovenzana V., Beghi R., Guidetti R., Innovative desalination plant based on the use of renewable energy sources, being published

Fratelli Mariani S.p.A. Lamiera stirata in stock, Catalogo tecnico.

Gazebo S.p.A. (2013) Progettazione e costruzione impianti di trattamento acque reflue, Catalogo tecnico prodotti. Hamed, M., Kabel, A., Omara, Z., \& Sharshir, S. (2014) Mathematical and experimental investigation of a solar humidification-dehumidification desalination unit, Desalination, Vol. 358, pp.9-17.

Kabeel, A.E., \& El-Said, E.M. (2013) Applicability of flashing desalination technique for small scale needs using a novel integrated system coupled with nanofluid-base solar collector, Desalination, Vol. 333, No. 1, pp.10-22.

Kang, H., Yang, Y., Chang, Z., Zheng, H., \& Duan, Z. (2014) Performance of a two-stage multi-effect desalination system based on humidification-dehumidification process, Desalination, Vol. 344, pp.339-349.

Lavanga, V., \& Farné, S. (2017) Patent n. 0001427399.

Lavanga, V., \& Farné, S. (2016) Patent n. 102015902343234.

Lavanga, V., \& Sparacino, A.C. (2013) Patent n. 0000275666.

Li, X., Yuan, G., Wang, Z., Li, H., \& Xu, Z. (2014) Experimental study on a humidification and dehumidification desalination system of solar air heater with evacuated tubes, Desalination, Vol. 351, pp.1-8.

Magrini, A., \& Magnani, L. (2009) Fisica Tecnica: Volume 1 - Esempi di calcolo di termodinamica e trasmissione del calore, CittàStudi Edizioni, Torino.

Manokar, A.M., Murugavel, K.K., \& Esakkimuthu, G. (2014) Different parameters affecting the rate of evaporation and condensation on passive solar still - A review, Ren. and Sust. En. Reviews, Vol. 38, pp.309-322.

Massarutto, A. (2008) L'acqua, Il Mulino, Bologna. 
Asian Journal of Applied Science and Technology

Volume 4, Issue 3, Pages 183-209, July-September 2020

Moran, M., Shapiro, H., Munson, B., \& DeWitt, D. (2011) Introduction to thermal systems engineering, McGraw Hill, New York.

Nagapadma M., Rakesh M., Nanditha N., Sushma K. M. \& Bhargavi K. S. (2019) Desalination of Seawater Using Graphene oxide Membrane, Asian Journal of Applied Science and Technology (AJAST), Volume 3, Issue 3, Pages 202-206, July-September 2019

Nam, W.K., Seockheon, L., Dooil, K., Seungkwan, H., \& Ji, H.K. (2011) Analyses of calcium carbonate scale deposition on four RO membranes under a seawater desalination condition, Water Science \& Technology Journal, Vol. 64, No. 8, pp.1573-1580.

Nematollahi, F., Rahimi, A., \& Gheinani, T.T. (2013) Experimental and theoretical energy and exergy analysis for a solar desalination system, Desalination, Vol. 317, pp.23-31.

Pantani, R. (2010) Effetti termici nelle trasformazioni. Principi di ingegneria chimica ambientale, Università di Salerno, Salerno.

Park, G.L., Schafer, A.I., \& Richards, B.S. (2012) The effect of intermittent operation on a wind-powered membrane system for brackish water desalination, Water Sci. \& Technology Journal, Vol. 65, No. 5, pp.867-874.

Ramadan, M.R., El-Sebali, A.A., Aboul-Enein, S., \& Khallaf, A.M. (2004) Experimental testing of a shallow solar pond with continuous extraction, Energy and Buildings, Vol. 36, No. 9, pp.955-964.

Reddy, S., \& Sharon, H. (2014) A review of solar energy driven desalination technologies, Elsevier, New York. Rognoni, M. (2010) La dissalazione dell'acqua di mare. Descrizione, analisi e valutazione delle principali tecnologie, Dario Flaccovio, Palerno.

Salata, F., \& Coppi, M. (2014) A first approach study on the desalination of sea water using heat transformer powered by solar ponds, Applied Energy, Vol. 136, pp.611-618.

Schafer, A.I., Remy, C., \& Richards, B.S. (2004) Performance of a small solar-powered hybrid membrane system for remote communities under varying feedwater salinities, Water Science \& Technology: Water Supply, Vol. 5, No. 5-6, pp.233-243.

Stiferite S.r.l. (2017) Prodotti \& soluzioni per edifici efficienti, Catalogo Tecnico.

Subramanian, S. (s.d.) Lecture notes on the estimation of binary diffusivities, Clarkson University, Clarkson.

Tang, M., Cox, R., \& Kalberer, M. (2014) Compilation and evaluation of gas phase diffusion coefficients of reactive trace gases in the atmosphere: volume 1. Inorganic compounds, Atmospheric Chemistry and Physics, Vol. 14, No. 17, pp.9233-9247.

Tzen, E., Zaragoza, G., \& Alarcòn Padilla, D.C. (2012) Solar Desalination, Comprehensive Renewable Energy, Vol. 3, pp.529-565.

UN Water (2016). 2016 UN World Water Development Report, Water and Jobs.

World Health Organization. (2017) Guidelines for drinking-water quality, United Nations, Geneva.

Yildirim, C., \& Solmus, I. (2014). A parametric study on a humidification-dehumidification desalination unit powered by a solar air and water heaters, Energy Conversion and Management, Vol. 86, pp.568-575. 